\title{
Temporal differences in the development of organ dysfunction based on two different approaches to induce experimental intra- abdominal hypertension in swine
}

\author{
Michael Moller ${ }^{1 *}$, Ulrik K Kjerkegaard ${ }^{2}$, Jens Rolighed Larsen ${ }^{3,4}$, Hanne Birke-Sorensen ${ }^{1,5}$, Lars B Stolle $e^{1,5}$
}

\begin{abstract}
Background: Intra-abdominal hypertension [IAH] occurs frequently among critically ill patients and is associated with increased mortality and organ failure. Two porcine models of IAH that cause abdominal compartment syndrome [ACS] with organ dysfunction were created. We investigated whether the two methods used to create $\mathrm{IAH}-\mathrm{CO}_{2}$ pneumoperitoneum or adding volume to the intra-abdominal space - exerted different impacts on the temporal development of organ dysfunction.

Methods: Twenty-four 40-kg female pigs were allocated to four groups: $25 \mathrm{mmHg} I \mathrm{AH}$ with $\mathrm{CO}_{2}$ pneumoperitoneum $(n=8),>20 \mathrm{mmHg}$ IAH caused by addition of volume $(n=8)$, and two corresponding sham groups (each $n=4)$. The two sham groups were later pooled into one control group $(n=8)$. The animals were monitored for $12 \mathrm{~h}$. Repeated serial measurements were taken of group differences over time and analyzed using analysis of variance.

Results: Thirty-eight percent of the animals $(n=3)$ in each intervention group died near the end of the 12-h experiment. Both intervention groups experienced kidney impairment: increased creatinine concentration $(P<0.0001)$, anuria $(P=0.0005)$, hyperkalemia $(P<0.0001)$, decreased abdominal perfusion pressure, and decreased dynamic lung compliance. $\mathrm{CO}_{2}$ pneumoperitoneum animals developed hypercapnia $(P<0.0001)$ and acidosis $(P<0.0001)$.

Conclusions: Both methods caused ACS and organ dysfunction within $12 \mathrm{~h}$. Hypercapnia and acidosis developed in the $\mathrm{CO}_{2}$ pneumoperitoneum group.
\end{abstract}

\section{Background}

The multiple organ dysfunction syndrome [MODS] is a major cause of death among patients with infection/sepsis and traumatic or surgical injury [1]. Intra-abdominal hypertension [IAH] occurs frequently among critically ill patients and is both a predictor of MODS [2] and associated with mortality and organ failure [3,4]. An increase in intra-abdominal pressure [IAP] $>20 \mathrm{mmHg}$ and associated new organ damage are referred to as the abdominal compartment syndrome [ACS] [5]. Prior studies

\footnotetext{
* Correspondence: moller0304@gmail.com

${ }^{1}$ Institute of Clinical Medicine, Aarhus University, Aarhus University Hospital,

Skejby, Brendstrupgaardsvej 100, Aarhus N, 8200, Denmark

Full list of author information is available at the end of the article
}

have shown that risk factors for the development of IAH and ACS include acute respiratory failure, abdominal surgery, sepsis, massive fluid resuscitation, and major trauma [6].

It is difficult to develop a single experimental animal model of MODS based on IAH, and unfortunately, the ideal model of ACS is not yet developed [7]. $\mathrm{CO}_{2}$ pneumoperitoneum generated by laparoscopic insufflation was used to generate IAH in experimental models [8-12]. $\mathrm{CO}_{2}$ pneumoperitoneum is known to impact the immune response in at least two ways: as a direct consequence of the peritoneal acidosis [13] and by causing systemic acidosis [14], which also influences the immune response [15]. Fluid-filled bags placed intra-abdominally were used

\section{SpringerOpen ${ }^{\circ}$}

(C) 2012 Moller et al.; licensee Springer This is an open access article distributed under the terms of the Creative Commons Attribution License (http://creativecommons.org/licenses/by/2.0), which permits unrestricted use, distribution, and reproduction in any medium, provided the original work is properly cited. 
to simulate IAH [16]. Both methods generate IAH and cause ACS, and might therefore produce MODS. The question remains whether there are differences in the effects that the models have on organ dysfunction.

The main aim of this study was to investigate differences in creating IAH by $\mathrm{CO}_{2}$ pneumoperitoneum or by adding volume to the intra-abdominal space using a fluid bag model. With IAH generated by laparoscopic $\mathrm{CO}_{2}$ insufflations in one model and volume added to the intra-abdominal cavity in another model, we could evaluate and compare the impacts on the kidneys, cardiovascular system, metabolism, and mortality.

\section{Materials and methods}

The investigation conformed to the Danish law for animal research (Act no. 1306 of 23/11/2007, Danish Ministry of Justice) and the guidelines from Guide for the Care and Use of Laboratory Animals, published by the U.S. National Institutes of Health (NIH Publication No. 85-23, revised 1996).

\section{Experimental setup}

The study was an experimental animal study performed at a university research laboratory. Twenty-four pigs were allocated to four groups: $\mathrm{IAH}$ with $\mathrm{CO}_{2}$ pneumoperitoneum [CO2] $(n=8), \mathrm{CO}_{2}$ pneumoperitoneum sham $(n=$ 4), IAH with intra-abdominal volume addition [VOL] $(n=$ $8)$, and intra-abdominal volume addition sham $(n=4)$. After all experiments were performed, we evaluated the data from the $\mathrm{CO} 2$ sham group and the VOL sham group at $T=0 \mathrm{~h}$ and $T=10 \mathrm{~h}$ for the following parameters: weight, diuresis, $\mathrm{pH}$, partial pressure of $\mathrm{CO}_{2}\left[\mathrm{pCO}_{2}\right]$, base excess, $\mathrm{K}^{+}$, lactate, heart rate, mean arterial pressure [MAP], mean pulmonary artery pressure [MPAP], central venous pressure $[\mathrm{CVP}]$, and creatinine. The groups were similar for all measured values except lactate $T=0 \mathrm{~h}$ (mean value for the three groups: control $=0.963, \mathrm{CO} 2=$ 0.863 , $\mathrm{VOL}=1.125)(P=0.03)$. Data from the $\mathrm{CO} 2$ sham group and the VOL sham group were therefore pooled into one control group $(n=8)$. After baseline measurements $(T=0 \mathrm{~h})$, the pigs were randomized to one of the four study groups, and the IAH induction procedure or the sham operation was performed. Sampling started at baseline $(T=0 \mathrm{~h})$ and continued with one sample per hour for $12 \mathrm{~h}(T=1 \mathrm{~h}$ to $T=12 \mathrm{~h})$. The following data were collected: (1) physiological parameters: intra-bladder pressure [IBP], heart rate, MAP, MPAP, CVP, abdominal perfusion pressure (APP = MAP - IAP), and tidal volume; (2) arterial blood samples: $\mathrm{pH}, \mathrm{pCO}_{2}$, base excess, $\mathrm{K}^{+}$, and lactate; and (3) venous blood samples: creatinine.

\section{Anesthesia}

The animals were female Danish Landrace pigs that had fasted for $24 \mathrm{~h}$ prior to the experiment and had free access to water. Prior to transportation to the institute, they received $0.5 \mathrm{mg} / \mathrm{kg}$ midazolam (Janssen Pharmaceutica, Beerse, Belgium) and $4 \mathrm{mg} / \mathrm{kg}$ azeperone (Janssen-Cilag $\mathrm{GmbH}$, Neuss, Germany) intramuscularly. General anesthesia was induced with an intramuscular injection of $4.35 \mathrm{mg} / \mathrm{kg}$ (S)-ketamine (Pfizer ApS, Ballerup, Denmark) and $0.375 \mathrm{mg} / \mathrm{kg}$ midazolam (Hameln Pharmaceuticals GmbH, Hameln, Germany) intravenously, followed by intubation. After intubation, the animals were ventilated via a respirator (Datex-Ohmeda S/5 Avance, GE Healthcare, Brøndby, Denmark). Sedation was maintained with sevoflurane (Abbott Scandinavia AB, Solna, Sweden) inhalation to obtain a minimal alveolar concentration of approximately 1.5 . Fentanyl was infused intravenously at a constant rate of $12.5 \mu \mathrm{g} / \mathrm{kg} / \mathrm{h}$. No muscular relaxant was used. Pressure-controlled respirator settings were used. Initial settings were a fraction of inspired oxygen $\left[\mathrm{FiO}_{2}\right]$ of 0.3 ; positive end-expiratory pressure [PEEP] of $4 \mathrm{~cm} \mathrm{H}_{2} 0$; inspiratory pressure $\left[P_{\text {insp }}\right]$ of $12 \mathrm{~cm} \mathrm{H}_{2} \mathrm{O}$, restricting peak airway pressure to a maximum of $16 \mathrm{~cm} \mathrm{H}_{2} \mathrm{O}$; respiratory frequency of $12 / \mathrm{min}$, and inhalation/expiration ration [I/E] of $1: 2$. Saline was infused at a constant rate of $1.5 \mathrm{ml} / \mathrm{kg} / \mathrm{h}$.

A 6Fr catheter was placed in the carotid artery using a cutdown technique for the measurement of arterial blood pressure and arterial blood sampling. An $8 \mathrm{Fr}$ catheter was placed in the right external jugular vein for infusions and to introduce a Swan-Ganz catheter $\left(\mathrm{CCOmbo}^{\circledR}\right.$, Edwards Lifesciences LLC, Irvine, CA, USA) connected to a Baxter Vigilance monitor (Edwards Life Sciences LLC, Irvine, CA, USA) in order to measure MPAP and CVP. A 7Fr catheter was placed in the left external jugular vein for venous blood sampling. The urinary bladder was catheterized using a 12G Foley catheter connected to an IBP measuring catheter (UnoMeter Abdo-Pressure, Unomedical, Birkerød, Denmark) and a sample tube to monitor diuresis. A rectal thermometer was inserted to measure core temperature. A pulse oximetry device was attached to the pig's tail to observe arterial blood oxygen saturation.

\section{Induction of intra-abdominal hypertension Induction of $\mathrm{IAH}$ with the $\mathrm{CO} 2$ group}

Verres Cannula was inserted below the umbilicus and attached to a laparoscopic $\mathrm{CO}_{2}$ insufflator (Thermoflator 26432020, Karl Storz, Holte, Denmark or Vision F103, Lemke, Berlin, Germany). The insufflator was set to IAP = $25 \mathrm{mmHg}$.

\section{Induction of IAH with the VOL group}

Via a $15-\mathrm{cm}$ incision above the umbilicus, seven 1-1 ordinary saline infusion bags were placed in the abdominal cavity. Bags were positioned into the small pelvis until IBP was above $20 \mathrm{mmHg}$. The abdominal wall was closed in two layers, including the fascia, using running sutures. 


\section{$\mathrm{CO}_{2}$ pneumoperitoneum sham group}

These animals underwent a procedure similar to the $\mathrm{CO} 2$ group, but Verres Cannula remained unattached to the insufflator.

\section{Intra-abdominal volume addition sham group}

The animals underwent a procedure similar to the VOL group, but empty saline bags were inserted into the abdominal cavity.

\section{Anesthesia maintenance and ventilator settings during experiment}

IAH decreases lung capacity and requires the adjustment of respirator settings to ensure sufficient ventilation. Our priorities were to maintain arterial oxygen saturation $>$ $90 \%, \mathrm{pCO}_{2}<5 \mathrm{kPa}, \mathrm{MAP}>60 \mathrm{mmHg}$, and a tidal volume of $400 \mathrm{ml}$. Initial respirator settings could be increased up to $\mathrm{F}_{\mathrm{i}} \mathrm{O}_{2}=0.7 ; \mathrm{PEEP}=8 \mathrm{~cm} \mathrm{H} \mathrm{H}_{2} \mathrm{O} ; P_{\text {insp }}=24$ $\mathrm{cm} \mathrm{H}_{2} \mathrm{O}$, restricting peak airway pressure to a maximum of $32 \mathrm{~cm} \mathrm{H} \mathrm{H}_{2} \mathrm{O}$; respiratory frequency $=24$; and $\mathrm{I} / \mathrm{E}=$ $1: 1.5$. Immediately following IAH generation, all respirator settings, except $\mathrm{F}_{\mathrm{i}} \mathrm{O}_{2}$, were adjusted to maximally allowed settings in order to avoid respiratory complications such as atelectasis. A 500-ml bag of Rheomacrodex ${ }^{\circledR} 100 \mathrm{mg} / \mathrm{ml}$ with saline was infused when arterial pressure was $<60 \mathrm{mmHg}$. Two bags of Rheomacrodex ${ }^{\circledR}$ (Meda A/S, Alleroed, Denmark) were allowed for each pig.

\section{Physiologic measurements}

A fixed point at bladder level was marked on the animals. Prior to IBP measurements, the bladder pressure-measuring catheter was elevated. This installed the fluid inside the catheter into the bladder, ensuring that the bladder was not empty when IBP was measured. The zero point of the IBP-measuring catheter was aligned with the marked point on the pig, and the catheter was held vertically. End-expiratory bladder pressure was noted. The animals were in supine position.

Arterial blood samples were analyzed on a blood gas analyzer (ABL 700 series, Radiometer, Copenhagen, Denmark). Heart rates and blood pressures were sampled and recorded through a computer connected to the respirator using software (Datex-Ohmeda S5 Collect Program, version 4.0, Datex-Ohmeda Division, Instrumentarium Corp, Helsinki, Finland). Venous blood samples were stored at $-20^{\circ} \mathrm{C}$, and the creatinine content was measured by trained personnel at Aarhus University Hospital. APP was calculated as MAP - IBP. Dynamic lung compliance [Cdyn] was calculated as tidal volume $/\left(P_{\text {insp }}-\mathrm{PEEP}\right)$.

\section{Statistics}

Repeated serial measurements were tested for group differences over time by univariate repeated measures using analysis of variance [ANOVA]. MedCalc 9.3.2.0
(MecCalc Software, Mariakerke, Belgium) and Intercooled STATA 9.2 (College Station, TX, USA) were used in the analyses. Furthermore, a Kruskal-Wallis one-way ANOVA on ranks using Dunn's method for multiple comparisons was performed between the three groups at corresponding moments. Sigmastat ${ }^{\mathrm{TM}}$ version 3.5 (Systat Software, San Jose, California, USA) was used in the analyses. The similarity between the two sham groups $\left(\mathrm{CO}_{2}\right.$ pneumoperitoneum sham group $(n=4)$ and the intra-abdominal volume addition sham group $(n=4))$ was tested with the Mann-Whitney rank sum test using SigmaStat ${ }^{\mathrm{TM}}$ version 3.11 (Systat Software, San Jose, California, USA) at two points: $T=0 \mathrm{~h}$ and $T=10 \mathrm{~h}$. For all analyses, a $P$ value of less than 0.05 was considered significant.

\section{Results}

\section{Baseline values}

No difference at baseline was observed between the three groups: control $(n=8), \mathrm{CO} 2(n=8)$, and VOL $(n=8)$ (Tables 1 and 2).

\section{Intra-bladder pressure and survival}

IBP in the control group was lower than that in the intervention groups $(P<0.0001$, repeated measures ANOVA. VOL group IBP differed from control at most other times than $T=12 \mathrm{~h}(P<0.05$, Kruskal-Wallis), data not presented). In both intervention groups, IBP was above $20 \mathrm{mmHg}$ and remained stable. CO2 group mean IBP was constantly 1 to $2 \mathrm{mmHg}$ above the 25 $\mathrm{mmHg}$ IAP to which the laparoscopic insufflators were adjusted. No animals died in the control group during the experiment. Three animals (38\%) died in each intervention group (Table 1).

\section{Acid-base status}

The pigs in the $\mathrm{CO} 2$ group showed a higher increase in $\mathrm{pCO}_{2}$ and decrease in $\mathrm{pH}$ than pigs in the two other groups throughout the experiment. Both intervention groups experienced decreasing base excess; for the $\mathrm{CO}_{2}$ group, this was observed throughout the experiment $(P<0.0001$, repeated measures ANOVA. VOL group base excess differed from control until $T=7 \mathrm{~h}(P<$ 0.05 , Kruskal-Wallis), data not presented) (Table 1 , Figure 1).

\section{Organ impact}

Kidney function was affected in a similar manner in both intervention groups, with increasing creatinine concentration and decreasing urine output, ending in anuria $(P<$ 0.0001, repeated measures ANOVA) (Table 1). Similarly, increases in $\mathrm{K}^{+}$concentration $(P<0.0001$, repeated measures ANOVA) and lactate concentration $(P=0.0007$, repeated measures ANOVA. CO2 group lactate was 
Table 1 Physiological parameters.

\begin{tabular}{|c|c|c|c|c|}
\hline Parameter & Group & $T=0 \mathrm{~h}$ (baseline) ${ }^{\mathrm{a}}$ & $T=12 \mathrm{~h}^{\mathrm{a}}$ & $P$ value $^{\mathrm{t}}$ \\
\hline \multirow[t]{3}{*}{$\mathrm{IBP}(\mathrm{mmHg})$} & Control & $5(2)$ & $7(1)$ & $<0.0001$ \\
\hline & $\mathrm{CO} 2$ & $5(2)$ & $26(1)^{c}$ & \\
\hline & VOL & $5(1)$ & $21(4)$ & \\
\hline \multirow[t]{3}{*}{ Survival (\%) } & Control & 100 & 100 & \\
\hline & $\mathrm{CO} 2$ & 100 & 63 & \\
\hline & VOL & 100 & 63 & \\
\hline \multirow[t]{3}{*}{$\mathrm{pCO}_{2}(\mathrm{kPa})$} & Control & $4.6(0.6)$ & $5.4(0.9)$ & $<0.0001$ \\
\hline & $\mathrm{CO} 2$ & $4.9(0.4)$ & $11.5(3.2)^{c}$ & \\
\hline & VOL & $4.5(0.5)$ & $7.4(4.5)$ & \\
\hline \multirow[t]{3}{*}{$\mathrm{pH}$} & Control & $7.5(0.1)$ & $7.5(0.1)$ & $<0.0001$ \\
\hline & $\mathrm{CO} 2$ & $7.5(0.0)$ & $7.1(0.1)^{c}$ & \\
\hline & VOL & $7.6(0.0)$ & $7.3(0.2)$ & \\
\hline \multirow[t]{3}{*}{ Base excess (mmol/l) } & Control & $7.0(0.8)$ & $4.4(1.3)$ & $<0.0001$ \\
\hline & $\mathrm{CO} 2$ & $7.0(1.2)$ & $-1.4(4.7)^{c}$ & \\
\hline & VOL & $7.5(1.3)$ & $-0.1(4.6)$ & \\
\hline \multirow[t]{3}{*}{ Creatinine $(\mathrm{mg} / \mathrm{dl})$} & Control & $1.4(0.3)$ & $1.9(0.5)$ & $<0.0001$ \\
\hline & $\mathrm{CO} 2$ & $1.4(0.3)$ & $3.8(0.7)^{c}$ & \\
\hline & VOL & $1.3(0.3)$ & $4.3(0.8)^{c}$ & \\
\hline \multirow[t]{3}{*}{ Diuresis (ml/h) } & Control & $48(38)$ & $38(22)$ & 0.0005 \\
\hline & $\mathrm{CO} 2$ & $43(24)$ & $1(2)^{c}$ & \\
\hline & VOL & $49(27)$ & $4(4)^{c}$ & \\
\hline \multirow[t]{3}{*}{$\mathrm{K}^{+}(\mathrm{mmol} / \mathrm{l})$} & Control & $4.7(1.0)$ & $4.6(0.5)$ & $<0.0001$ \\
\hline & $\mathrm{CO} 2$ & $4.4(0.5)$ & $7.6(1.1)^{c}$ & \\
\hline & VOL & $4.1(0.3)$ & $8.2(0.4)^{c}$ & \\
\hline \multirow[t]{3}{*}{ Lactate $(\mathrm{mmol} / \mathrm{l})$} & Control & $1.0(0.3)$ & $0.8(0.4)$ & 0.0007 \\
\hline & $\mathrm{CO} 2$ & $0.9(0.2)$ & $3.6(3.1)$ & \\
\hline & VOL & $1.1(0.4)$ & $3.1(3.3)^{c}$ & \\
\hline
\end{tabular}

${ }^{a}$ Data presented as mean \pm standard deviation $\left[\mathrm{SD}\right.$ ]. Control, control group; $\mathrm{CO} 2$, group with $\mathrm{CO}_{2}$ pneumoperitoneum; VOL, group with intra-abdominal volume addition by placement of saline bags. Statistics: group-time interactions were analyzed by repeated measures ANOVA. 'Difference between groups over time. Kruskal-Wallis one-way ANOVA on ranks using Dunn's method for multiple comparisons between groups at corresponding moments, 'different from control,. For survival, no statistically significant different odds ratios were observed: control vs. VOL $=10.8(P=0.14)$, control vs. CO2 $=6.5(P=0.25)$, VOL vs. CO2 $=1.8(P=$ 0.59). IBP, intra-bladder pressure; $\mathrm{pCO}_{2}$, partial pressure of $\mathrm{CO}_{2}$.

Table 2 Hemodynamic and pulmonary parameters.

\begin{tabular}{|c|c|c|c|c|}
\hline Parameter & Group & $T=0 \mathrm{~h}$ (baseline) ${ }^{\mathrm{a}}$ & $T=12 \mathrm{~h}^{\mathrm{a}}$ & $P$ value $^{\mathrm{b}}$ \\
\hline \multirow[t]{3}{*}{ Heart rate (beats/min) } & Control & $71(13)$ & $92(28)$ & $<0.0001$ \\
\hline & $\mathrm{CO} 2$ & $81(23)$ & $140(35)$ & \\
\hline & VOL & $65(10)$ & $91(14)$ & \\
\hline \multirow[t]{3}{*}{ CVP $(\mathrm{mmHg})$} & Control & $3(2)$ & $5(3)$ & $<0.0001$ \\
\hline & $\mathrm{CO} 2$ & $2(3)$ & $9(2)$ & \\
\hline & VOL & $5(3)$ & $16(7)^{c}$ & \\
\hline \multirow[t]{3}{*}{ MPAP $(\mathrm{mmHg})$} & Control & $11(4)$ & $17(6)$ & 0.0195 \\
\hline & $\mathrm{CO} 2$ & $12(3)$ & $27(10)$ & \\
\hline & VOL & $13(3)$ & $27(9)$ & \\
\hline \multirow[t]{3}{*}{ MAP (mmHg) } & Control & $59(10)$ & $60(3)$ & 0.0012 \\
\hline & $\mathrm{CO} 2$ & $58(11)$ & $57(5)$ & \\
\hline & VOL & $68(12)$ & $56(11)$ & \\
\hline \multirow[t]{3}{*}{ APP $(\mathrm{mmHg})$} & Control & $53(9)$ & $55(4)$ & $<0.0001$ \\
\hline & $\mathrm{CO} 2$ & $54(11)$ & $31(6)^{c}$ & \\
\hline & VOL & $64(12)$ & $39(3)^{c}$ & \\
\hline Cdyn $\left(\mathrm{ml} / \mathrm{cm} \mathrm{H} \mathrm{H}_{2} \mathrm{O}\right)$ & Control & $33(4)$ & $26(5)$ & $<0.0001$ \\
\hline
\end{tabular}




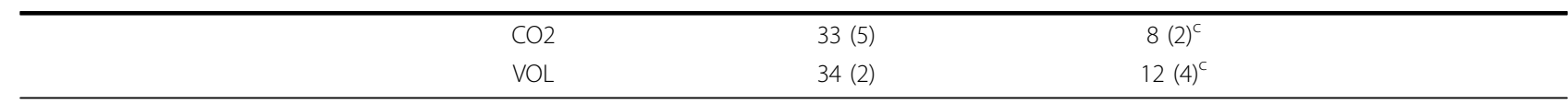

${ }^{\mathrm{a}}$ Data presented as mean $\pm \mathrm{SD}$. Control, control group; $\mathrm{CO} 2$, group with $\mathrm{CO}_{2}$ pneumoperitoneum; VOL, group with intra-abdominal volume addition by placement of saline bags. Statistics: group-time interactions were analyzed by repeated measures ANOVA. ${ }^{\mathrm{b}} P$ value, difference between groups over time. Kruskal-Wallis one-way ANOVA on ranks using Dunn's method for multiple comparisons between groups at corresponding moments, 'different from control, CVP, central venous pressure; MPAP, mean pulmonary artery pressure; MAP, mean arterial pressure; APP, abdominal perfusion pressure; Cdyn, dynamic lung compliance.

different from control at $T=10$ to $11 \mathrm{~h}(P<0.05$, KruskalWallis), data not presented) were found in both intervention groups (Table 1, Figure 2).

\section{Circulatory effects}

Heart rate was continually increasing in the CO2 group; the VOL group heart rate initially increased and then decreased. The VOL group CVP increased during the last part of the experiment, and MPAP increased in both intervention groups $(P<0.0001$ for heart rate and CVP, $P=0.0195$ for MPAP, repeated measures ANOVA. VOL and CO2 group MPAP were different from control at multiple other times than $T=12 \mathrm{~h}(P<$ 0.05 , Kruskal-Wallis), data not presented). MAP was increased in the $\mathrm{CO} 2$ group during the initial part of the experiment $(P=0.0012$, repeated measures ANOVA) but later decreased. APP was decreased in both experimental groups $(P<0.0001$, repeated measures ANOVA) (Table 2, Figure 3).

\section{Pulmonary function}

Respirator settings were changed immediately after IAH induction to maintain or to counteract decreasing tidal volume and saturation and increasing $\mathrm{pCO}_{2}$. Cdyn was immediately decreased in both experimental groups and remained stable $(P<0.0001$, repeated measures ANOVA) (Table 2, Figure 1). At the end of the experiment, the lungs were macroscopically inspected, and the basal posterior parts were darker than the rest of the lungs.

\section{Discussion}

In this study, we investigated whether the choice of a method to create IAH, either $\mathrm{CO}_{2}$ pneumoperitoneum or addition of volume to the intra-abdominal cavity, had any impact on the development of organ dysfunction. We observed both the specific organ damage generated and the temporal development of organ damage.

\section{Main results}

Our results showed that both methods of generating IAH produce ACS [5]. Our finding that three animals (38\%) died in each group toward the end of the experiment demonstrates that the animals sustained organ damage. The development of organ dysfunction was found to be simultaneous for creatinine increase, $\mathrm{K}^{+}$ increase, MPAP, and Cdyn. Both intervention groups needed an immediate change in respirator settings after IAH generation to ensure sufficient ventilation. Both intervention groups ended up with APP $<50 \mathrm{mmHg}$, which is below the suggested recommendations [6]. All findings observed changed throughout study, except Cdyn which immediately decreased and then remained stable. The major differences between the models were hypercapnia and acidosis observed in the animals with $\mathrm{CO}_{2}$ pneumoperitoneum. Other differences included different temporal development of lactate increase, initial VOL group tachycardia, the VOL group's CVP increase after $8 \mathrm{~h}$, and initially higher MAP in the CO2 group.

Previous studies on IAH, both clinical and experimental, demonstrate an impact on organs similar to our findings. Kidney damage is known to appear as an early sign of organ damage during IAH and ACS [4,17]. Experimentally decreased blood flow in the peritubular capillaries has been shown [10], as well as redistribution of blood away from the kidneys [11] during IAH. Among IAH/ACS patients, impaired respiratory function and the need for mechanical ventilation are well-known complications $[3,4,17]$. In a previously published study regarding $\mathrm{IAH}$ generated by $\mathrm{CO}_{2}$ pneumoperitoneum in pigs, all animals survived for $24 \mathrm{~h}$ [8], which is a much higher survival rate than we found.

Control animals experienced increased creatinine concentration, heart rate, and CVP. Nevertheless, these were minor changes and probably caused by the sham operative procedures. Accordingly, significant difference in organ damage between the control group and the intervention groups must be caused by IAH. Furthermore, control animals showed no increase in IBP after the sham procedures. Therefore, these animals must have been sedated to such a degree that muscle contractions did not increase the IAP. Any IAH observed in our animals was thus likely to be caused by the $\mathrm{CO}_{2}$ insufflations or the placement of extra volume in the experimental groups.

\section{Comparison of models}

The excess $\mathrm{pCO}_{2}$ in the $\mathrm{CO}_{2}$ group was most likely caused by the absorption of $\mathrm{CO}_{2}$ inserted into the abdominal cavity with the laparoscopic insufflator. This 


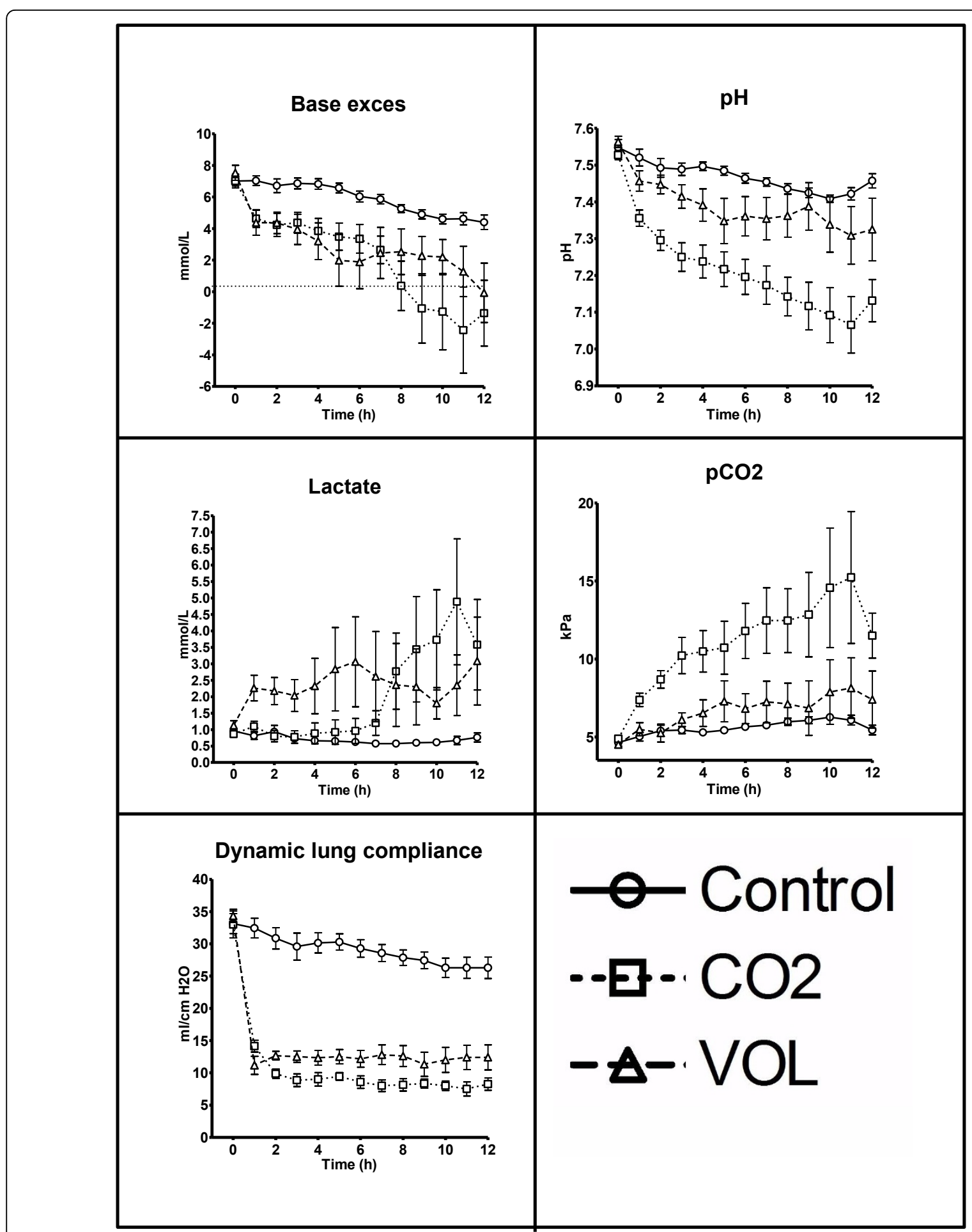

Figure 1 Metabolic and respiratory parameters. Data presented as mean \pm standard error of the mean [SEM]. Control, control group; CO2, group with $\mathrm{CO}_{2}$ pneumoperitoneum; VOL, group with intra-abdominal volume addition by placement of saline bags.

effect is already known [14]. All changes in acid-base status occurred despite our attempts to ensure sufficient ventilation, as described in the 'Materials and methods' section. Base excess was lowered almost equally in both our experimental groups. This could mean that the maximum capacity of metabolic compensation for 


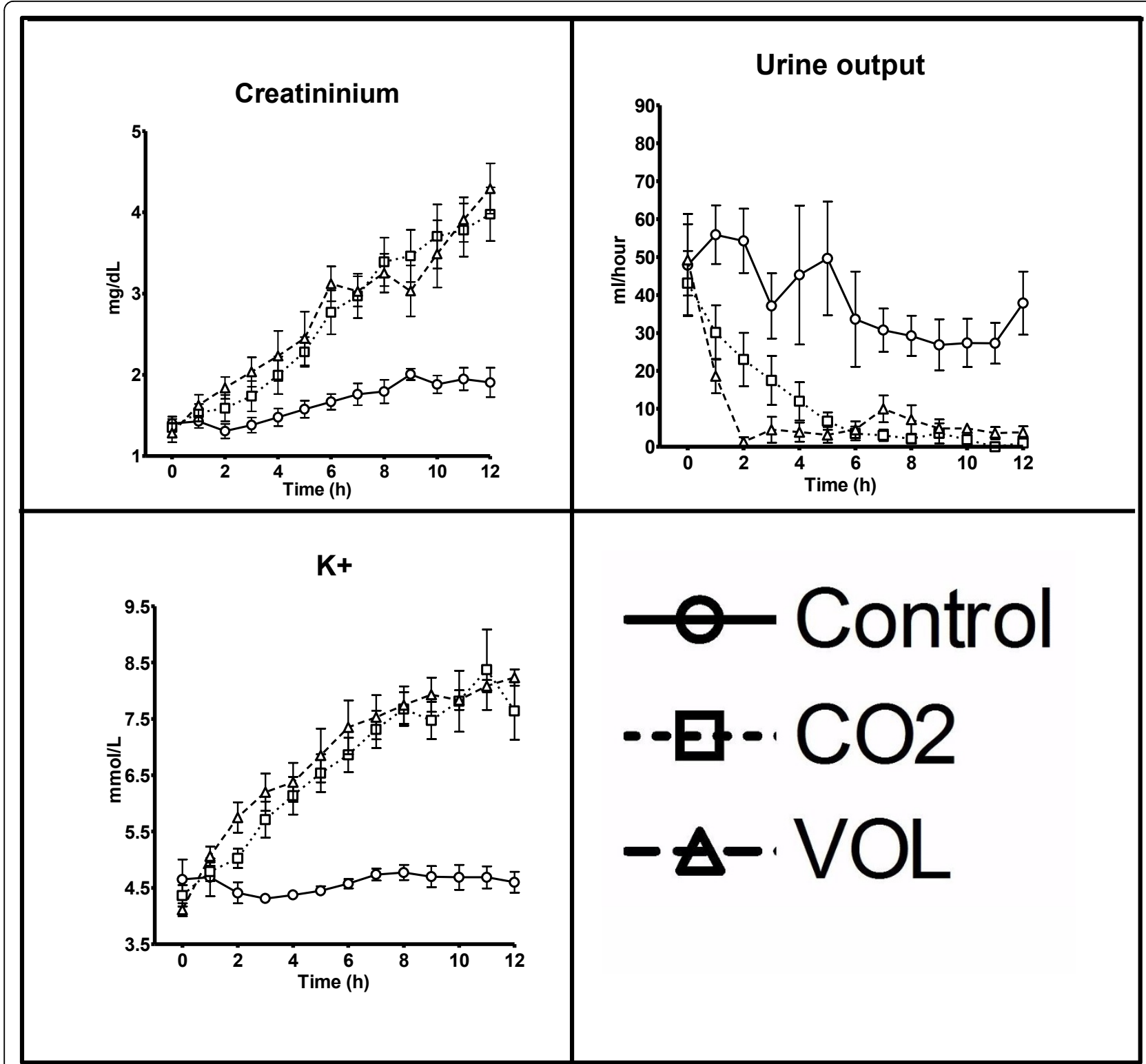

Figure 2 Renal parameters. Data presented as mean \pm SEM. Control, control group; $\mathrm{CO}$, group with $\mathrm{CO}_{2}$ pneumoperitoneum; VOL, group with intra-abdominal volume addition by placement of saline bags.

acidosis was reached in the $\mathrm{CO} 2$ group. In addition, the anuria precluded metabolic compensatory mechanisms that require functioning kidneys.

After initial IAH generation in the VOL group, we found no further IBP increase. Cheatham et al. stated: 'The more the degree of IAH, the more urgent is the need for decompression of the abdomen...' [6]. Since the animals suffered multiple organ damage, an increase in IBP might be expected to resemble the deteriorating condition. We did not observe this.

Comparing IAP with IBP in the $\mathrm{CO} 2$ group showed that IBP was constantly 1 to $2 \mathrm{mmHg}$ above IAP. In the VOL model, the IBP was slightly lower than that in the
$\mathrm{CO} 2$ group. The reason for this was that the abdominal cavity of our animals could only hold seven saline bags, producing an IBP of $22 \mathrm{mmHg}$. The lower IBP in the VOL group could result in less impact than if the IBP had been as high as in the $\mathrm{CO} 2$ group.

Both methods used to generate IAH are easy to apply. Pneumoperitoneum will rarely be the cause of real-life IAH. The VOL method is therefore probably closer to resembling pathological IAH than the $\mathrm{CO}_{2}$ method. Because acidosis is part of MODS, the $\mathrm{CO} 2$ model could be used if acidosis is desired in a given experiment. Care must be taken, however, not to confuse artificial with pathologic acidosis. 


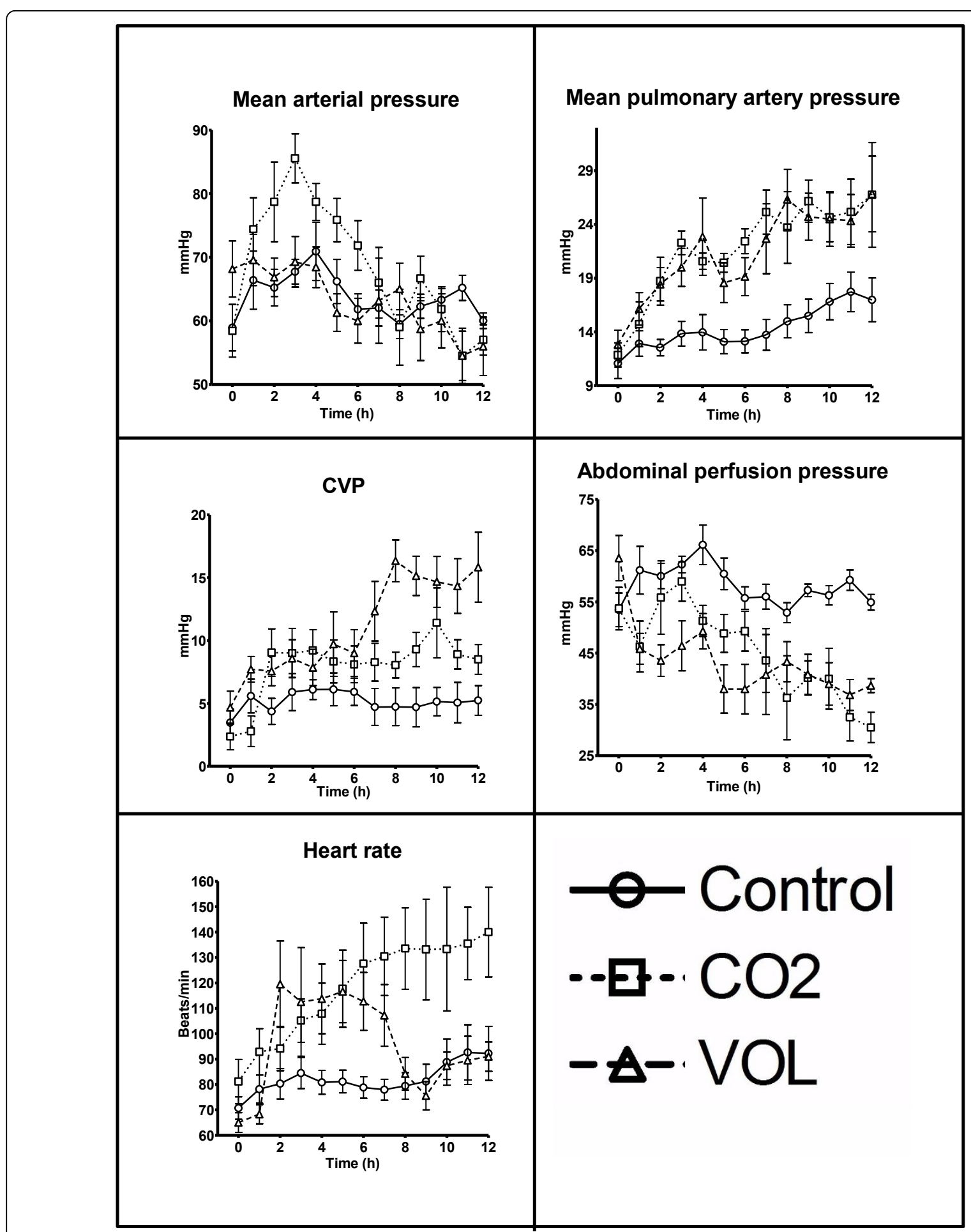

Figure 3 Cardiovascular parameters. Data presented as mean \pm SEM. Control, control group; $\mathrm{CO}_{2}$, group with $\mathrm{CO}_{2}$ pneumoperitoneum; VOL, group with intra-abdominal volume addition by placement of saline bags.

\section{Limitations}

After approximately $8 \mathrm{~h}$ of IAH, unexplained results were observed. Base excess became lower in the $\mathrm{CO} 2$ group than in the VOL group; the $\mathrm{CO} 2$ group's lactate increased from baseline values; the VOL group heart rate decreased back to baseline level; and CVP increased. We are unable to explain these results, yet we cannot rule out that the model was unstable, which 
would introduce a bias. Better monitoring of loading conditions in animals by monitoring cardiac output or pulmonary artery occlusion pressure would have provided valuable information that might reveal why heart rate and CVP developed as they did. Measurement of esophageal pressure could provide information regarding the relation between intra-thoracic pressure and the observed changes in CVP. Monitoring cytokines could also have provided valuable information about the animals' condition during ACS development. IBP was not measured as recommended: at the mid-axillary line at the iliac crest with not more than $25 \mathrm{ml}$ of intravesicular volume [5]. We measured IBP at the symphysis pubis and did not have control over the intravesical volume.

We only included eight animals in each group. This small number makes observations vulnerable to bias caused by few outlier animals. Toward the end of the experiment, the animals died in the IAH groups. It may have influenced results that data regarding the sickest animals were not included in the analytical evaluation after their deaths. This could explain the $\mathrm{CO} 2$ group's decreasing $\mathrm{pCO}_{2}$ and $\mathrm{K}^{+}$at $12 \mathrm{~h}$.

A drawback of the VOL method is the inability to ensure that the intra-abdominally bags are placed in the same position in every experiment. This may result in nonuniform pressure transmission producing a local pelvic compartment syndrome. Combining IBP and intragastric pressure could provide further information on this issue [18]. Another drawback when using saline bags is that the bags' borders are not smooth. They may cause bleeding or inflammation if the sharp parts interfere with surrounding tissues or vessels. We did not perform post-mortem examinations for organ or vessel damage.

\section{Conclusion}

Our study showed that IAH generated with either of two methods: $\mathrm{CO}_{2}$ pneumoperitoneum or intra-abdominal placement of saline bags, causes abdominal compartment syndrome and organ dysfunction within $12 \mathrm{~h}$. The animals subjected to $\mathrm{CO}_{2}$ pneumoperitoneum developed artificial hypercapnia and acidosis.

\section{Endnotes}

The work was performed at the Institute of Clinical Medicine, Aarhus University, Aarhus University Hospital, Skejby, Denmark.

\section{Abbreviations}

ACS: abdominal compartment syndrome; ANOVA: analysis of variance; APP: abdominal perfusion pressure; Cdyn: dynamic lung compliance; $\mathrm{CO} 2$ : group with $\mathrm{IAH}$ with $\mathrm{CO}_{2}$ pneumoperitoneum; CVP: central venous pressure; $\mathrm{IAH}$ : intra-abdominal hypertension; IAP: intra-abdominal pressure; IBP: intrabladder pressure; MAP: mean arterial pressure; MODS: multiple organ dysfunction syndrome; MPAP: mean pulmonary artery pressure; $\mathrm{PCO}_{2}$ : Partial pressure of carbon dioxide;PEEP: positive end-expiratory pressure; $P_{\text {insp: }}$ : inspiratory pressure; VOL: group with IAH with intra-abdominal volume addition.

\section{Acknowledgements}

This article has been published as part of Annals of Intensive Care Volume 2 Supplement 1, 2012: Diagnosis and management of intra-abdominal hypertension and abdominal compartment syndrome. The full contents of the supplement are available online at http://www.annalsofintensivecare. com/supplements/2/S1

This project was financially supported by The Danish Council for Independent Research, Medical Sciences.

\section{Author details}

${ }^{1}$ Institute of Clinical Medicine, Aarhus University, Aarhus University Hospital, Skejby, Brendstrupgaardsvej 100, Aarhus N, 8200, Denmark. ${ }^{2}$ Aarhus University, Aarhus C, 8000, Denmark. ${ }^{3}$ T-research, Department of Cardiothoracic and Vascular Surgery, Aarhus University Hospital, Skejby, Brendstrupgaardsvej 100, Aarhus N, 8200, Denmark. ${ }^{4}$ Department of Anesthesiology-Intensive Care, Aarhus University Hospital, Skejby, Brendstrupgaardsvej 100, Aarhus N, 8200, Denmark. ${ }^{5}$ Department of Plastic Surgery, Aarhus University Hospital, Aarhus C, 8000, Denmark.

\section{Authors' contributions}

MM performed the pilot studies, participated in the design of the study and the experiments, performed the experiments, drafted the samples, reviewed and analyzed the data, performed some of the statistical analysis, and wrote and submitted the manuscript. UKK took part in designing the experiments, in performing the pilot studies and experiments, and in drafting the samples. JRL participated in the design of the study and the experiments, designed the anesthesiological setup for the experiments, performed some of the statistical analysis and graphical presentations, and critically revised the manuscript. HBS and LBS took part in the design of the study and the experiments and critically revised the manuscript. All authors' contributions meet the criteria to justify authorship. All authors read and approved the final manuscript.

\section{Competing interests}

The authors declare that they have no competing interests.

Published: 5 July 2012

\section{References}

1. Barie PS, Hydo LJ, Pieracci FM, Shou J, Eachempati SR: Multiple organ dysfunction syndrome in critical surgical illness. Surg Infect (Larchmt) 2009, 10:369-377.

2. Balogh Z, McKinley BA, Holcomb JB, Miller CC, Cocanour CS, Kozar RA, Valdivia A, Ware DN, Moore FA: Both primary and secondary abdominal compartment syndrome can be predicted early and are harbingers of multiple organ failure. J Trauma 2003, 54:848-861.

3. Malbrain ML, Chiumello D, Pelosi P, Bihari D, Innes R, Ranieri VM, Del Turco M, Wilmer A, Brienza N, Malcangi V, Cohen J, Japiassu A, De Keulenaer BL, Daelemans R, Jacquet L, Laterre PF, Frank G, de Souza P, Cesana $B$, Gattinoni $L$ : Incidence and prognosis of intraabdominal hypertension in a mixed population of critically ill patients: a multiplecenter epidemiological study. Crit Care Med 2005, 33:315-322.

4. Vidal MG, Ruiz Weisser J, Gonzalez F, Toro MA, Loudet C, Balasini C, Canales $H$, Reina R, Estenssoro E: Incidence and clinical effects of intraabdominal hypertension in critically ill patients. Crit Care Med 2008, 36:1823-1831.

5. Malbrain ML, Cheatham ML, Kirkpatrick A, Sugrue M, Parr M, De Waele J, Balogh Z, Leppaniemi A, Olvera C, Ivatury R, D'Amours S, Wendon J, Hillman K, Johansson K, Kolkman K, Wilmer A: Results from the international conference of experts on intra-abdominal hypertension and abdominal compartment syndrome. I. Definitions. Intensive Care Med 2006, 32:1722-1732.

6. Cheatham ML, Malbrain ML, Kirkpatrick A, Sugrue M, Parr M, De Waele J, Balogh Z, Leppaniemi A, Olvera C, Ivatury R, D'Amours S, Wendon J, Hillman K, Wilmer A: Results from the international conference of experts on intra-abdominal hypertension and abdominal compartment syndrome. II. Recommendations. Intensive Care Med 2007, 33:951-962. 
7. Schachtrupp A, Wauters J, Wilmer A: What is the best animal model for ACS? Acta Clin Belg Suppl 2007, 225-232.

8. Toens C, Schachtrupp A, Hoer J, Junge K, Klosterhalfen B, Schumpelick V: A porcine model of the abdominal compartment syndrome. Shock 2002, 18:316-321.

9. Olofsson PH, Berg S, Ahn HC, Brudin LH, Vikstrom T, Johansson KJ: Gastrointestinal microcirculation and cardiopulmonary function during experimentally increased intra-abdominal pressure. Crit Care Med 2009, 37:230-239.

10. Sassa N, Hattori R, Yamamoto T, Kato M, Komatsu T, Matsukawa Y, Funahashi Y, Gotoh M: Direct visualization of renal hemodynamics affected by carbon dioxide-induced pneumoperitoneum. Urology 2009, 73:311-315.

11. Wauters J, Claus P, Brosens N, McLaughlin M, Malbrain M, Wilmer A: Pathophysiology of renal hemodynamics and renal cortical microcirculation in a porcine model of elevated intra-abdominal pressure. J Trauma 2009, 66:713-719.

12. Gudmundsson FF, Heltne JK: Respiratory changes during prolonged increased intra-abdominal pressure in pigs. Acta Anaesthesiol Scand 2004, 48:463-468.

13. Hanly EJ, Aurora AA, Shih SP, Fuentes JM, Marohn MR, De Maio A Talamini MA: Peritoneal acidosis mediates immunoprotection in laparoscopic surgery. Surgery 2007, 142:357-364.

14. Baratz RA, Karis JH: Blood gas studies during laparoscopy under general anesthesia. Anesthesiology 1969, 30:463-464.

15. Curley G, Contreras MM, Nichol AD, Higgins BD, Laffey JG: Hypercapnia and acidosis in sepsis: a double-edged sword? Anesthesiology 2010, 112:462-472.

16. Benninger $E$, Laschke MW, Cardell M, Keel M, Seifert B, Trentz O, Menger MD, Meier C: Intra-abdominal pressure development after different temporary abdominal closure techniques in a porcine model. $J$ Trauma 2009, 66:1118-1124.

17. Malbrain ML, Chiumello D, Pelosi P, Wilmer A, Brienza N, Malcangi V, Bihari D, Innes R, Cohen J, Singer P, Japiassu A, Kurtop E, De Keulenaer BL, Daelemans R, Del Turco M, Cosimini P, Ranieri M, Jacquet L, Laterre PF, Gattinoni L: Prevalence of intra-abdominal hypertension in critically ill patients: a multicentre epidemiological study. Intensive Care Med 2004, 30:822-829.

18. Malbrain ML, De Laet IE, Willems A, Van Regenmortel N, Schoonheydt K Dits $\mathrm{H}$ : Localised abdominal compartment syndrome: bladder-overgastric pressure ratio (B/G ratio) as a clue to diagnosis. Acta Clin Belg 2010, 65:98-106

doi:10.1186/2110-5820-2-S1-S16

Cite this article as: Moller et al:: Temporal differences in the development of organ dysfunction based on two different approaches to induce experimental intra-abdominal hypertension in swine. Annals of Intensive Care 2012 2(Suppl 1):S16.

\section{Submit your manuscript to a SpringerOpen ${ }^{\circ}$ journal and benefit from:}

- Convenient online submission

- Rigorous peer review

- Immediate publication on acceptance

- Open access: articles freely available online

- High visibility within the field

- Retaining the copyright to your article

Submit your next manuscript at $>$ springeropen.com 